\title{
Rhythmically Active Enkephalin-Expressing GABAergic Cells in the CA1 Area of the Hippocampus Project to the Subiculum and Preferentially Innervate Interneurons
}

\author{
Pablo Fuentealba, ${ }^{1}$ Ryohei Tomioka, ${ }^{1,2}$ Yannis Dalezios, ${ }^{1,3,4}$ László F. Márton, ${ }^{1,5}$ Michele Studer, ${ }^{6}$ Kathleen Rockland, ${ }^{2}$ \\ Thomas Klausberger, ${ }^{1}$ and Peter Somogyi ${ }^{1}$ \\ ${ }^{1}$ Medical Research Council Anatomical Neuropharmacology Unit, Department of Pharmacology, University of Oxford, Oxford OX1 3TH, United Kingdom, \\ ${ }^{2}$ Laboratory of Cortical Organization and Systematics, RIKEN Brain Science Institute, Wako, Saitama 351-0198, Japan, ${ }^{3}$ Department of Basic Sciences, \\ Faculty of Medicine, University of Crete, GR-71003 Heraklion, Greece, ${ }^{4}$ Institute of Applied and Computational Mathematics, Foundation of Research and \\ Technology-Hellas, GR-71110 Heraklion, Greece, ${ }^{5}$ Neural Systems Research Group, Sapientia-Hungarian University of Transylvania, Targu Mures, \\ Romania, and ${ }^{6}$ Telethon Institute of Genetics and Medicine, 80131 Naples, Italy
}

Enkephalins (ENKs) are endogenous opioids that regulate synaptic excitability of GABAergic networks in the cerebral cortex. Using retrograde tracer injections in the subiculum, we identified a hippocampal population of ENK-expressing projection neurons. In situ hybridization for GAD shows that ENK-expressing cells are a small GABAergic subpopulation. Furthermore, by extracellular recording and juxtacellular labeling in vivo, we identified an ENK-expressing cell in stratum radiatum of the CA1 area by its complete axodendritic arborization and characteristic spike timing during network oscillations. The somatodendritic membrane was immunopositive for mGluR $1 \alpha$, and there was both a rich local axon in CA1 and subicular-projecting branches. The boutons showed cell-type- and layerspecific innervation, i.e., interneurons were the main targets in the alveus, both interneurons and pyramidal cell dendrites were innervated in the other layers, and interneurons were exclusive targets in the subiculum. Parvalbumin-, but not somatostatin-, calbindin-, or cholecystokinin-expressing interneurons were preferred synaptic targets. During network activity, the juxtacellularly labeled ENKexpressing cell was phase modulated throughout theta oscillations, but silenced during sharp-wave/ripple episodes. After these episodes the interneuron exhibited rebound activity of high-frequency spike bursts, presumably causing peptide release. The ENK-expressing interneurons innervating parvalbumin-positive interneurons might contribute to the organization of the sharp-wave/ripple episodes by decreased firing during and rebound activity after the ripple episodes, as well as to the coordination of activity between the CA1 and subicular areas during network oscillations.

Key words: interneuron; hippocampus; subiculum; in vivo; enkephalin; extracellular recordings

\section{Introduction}

Enkephalins are oligopeptides that act as potent endogenous ligands of opioid receptors in the CNS (Hughes et al., 1975). In the hippocampus, opioid receptors activate G-protein-mediated transduction cascades, inhibiting $\mathrm{Ca}^{2+}$ conductances and activating $\mathrm{K}^{+}$conductances, presynaptically and postsynaptically,

Received May 5, 2008; revised July 16, 2008; accepted Aug. 20, 2008.

This work was supported by Interdevo Grant LSHM-CT-2004-005139 in the Framework 6 program of the European Union. T.K. was supported by Austrian Science Fund Grant P16637-B02. We thank Dr. Marisela Morales for guidance in in situ hybridization experiments, László Acsády and Istuán Katona for their helpful comments on an earlier version of this manuscript, and Kristina Detzner, Ben Micklem, David Roberts, and Wai Yee Suen for excellent technical assistance. We thank the following scientists for their generous gifts of antibodies: K. G. Baimbridge (antibody to parvalbumin), A. Buchan (to somatostatin), T. Gorcs (to VIP), T. Kaneko (to PPE), E. Mugnaini (to GAD), W. Sieghart (to GABA $R-\alpha 1$ ), A. Varro (to pro-CCK), and M. Watanabe (to CB1 receptor, mGluR1 $\alpha$, VIAAT). Antibody 9303 raised against CCK was provided by CURE/Digestive Diseases Research Center, Antibody/RIA Core (National Institutes of Health Grant DK41301).

Correspondence should be addressed to either Pablo Fuentealba or Peter Somogyi, Medical Research Council Anatomical Neuropharmacology Unit, Department of Pharmacology, University of Oxford, Mansfield Road, Oxford 0X13TH, UK. E-mail: pablo.fuentealba@pharm.ox.ac.uk or peter.somogyi@pharm.ox.ac.uk.

DOI:10.1523/JNEUROSCI.2052-08.2008

Copyright $\odot 2008$ Society for Neuroscience $\quad 0270-6474 / 08 / 2810017-06 \$ 15.00 / 0$ which results in the selective inhibition of GABAergic circuits and the consequent disinhibition of pyramidal cell activity (Zieglgänsberger et al., 1979; Madison and Nicoll, 1988; Pang and Rose, 1989). At the systemic level, the importance of the opioid system is revealed in the multitude of effects obtained by the application of endogenous and exogenous opioids; for example, related to analgesia, respiratory depression, euphoria, feeding, hormone release, gastrointestinal transit inhibition, and anxiety (Waldhoer et al., 2004).

Enkephalins are supplied to the hippocampal CA1 area from both intrinsic GABAergic interneurons and the extrinsic entorhinal cortical input (Gall et al., 1981). In the CA1 area, ENKexpressing GABAergic cells have been described as a homogeneous population, constituting one of the interneuron-selective cell types exclusively innervating other GABAergic neurons (Blasco-Ibáñez et al., 1998). As a result, ENK-expressing cells have been considered as a local-circuit GABAergic population modulating activity in the CA1 area.

A large diversity of nonpyramidal GABAergic cells in the hippocampus, however, project to the medial septum and/or retro- 
hippocampal areas (Jinno and Kosaka, 2002; Ferraguti et al., 2005). Overall, at least seven types of GABAergic projection neuron are predicted to coexist in the CA1 area (Jinno et al., 2007), but ENK-expressing cells have not been identified among them.

Here, we report a population of ENK-expressing cells projecting from the CA1 area to the subiculum and exhibiting distinct spike timing during network oscillations. Their large axonal arborization innervates selectively certain types of interneuron.

\section{Materials and Methods}

All procedures involving experimental animals were performed in accordance with the Animals (Scientific Procedures) Act of 1986 (United Kingdom) and associated procedures.

In situ hybridization for GAD with immunocytochemistry. Labeling was performed as described previously (Morales and Bloom, 1997). Briefly, free-floating cryostat sections from two adult male Sprague Dawley rats $(200-250 \mathrm{~g})$ were prehybridized for $3 \mathrm{~h}$ at $55^{\circ} \mathrm{C}$ in hybridization buffer, then hybridized at $55^{\circ} \mathrm{C}$ for $16 \mathrm{~h}$ in hybridization buffer containing $\left[{ }^{35} \mathrm{~S}\right]$ and $\left[{ }^{33} \mathrm{P}\right]$-labeled single-stranded RNA probes at $10^{7} \mathrm{cpm} / \mathrm{ml}$. After appropriate treatments, the sections were incubated with guinea pig antiproenkephalin antibody $(0.4 \mu \mathrm{g} / \mathrm{ml})$, which was visualized with an $\mathrm{ABC}$ kit (Vector Laboratories) and peroxidase reaction. The sections were mounted, dipped in nuclear track emulsion, and exposed for several weeks before development.

Preparation and injection of recombinant adenovirus vector. Approved protocols (Safety Division, RIKEN Institute) were performed in biosafety level 2 rooms in accordance with National Institutes of Health Guidelines for Research Involving Recombinant DNA Molecules. The vector is based on human adenovirus type 5, and expresses enhanced green fluorescent protein (EGFP) under the control of a neuron-specific promoter synapsin I (Tomioka and Rockland, 2006).

Four adult male Sprague Dawley rats $(200-250$ g) were anesthetized with chloral hydrate $(350 \mathrm{mg} / \mathrm{kg})$. The virus $\left(0.2-0.3 \mu \mathrm{l}\right.$ of $1.0 \times 10^{12}$ $\mathrm{pfu} / \mathrm{ml})$ was injected stereotaxically through a micropipette $(15-20 \mu \mathrm{m}$ tip) by pressure injection into the dorsal subiculum (from bregma: 5.8 $\mathrm{mm}$ posterior, $2.0 \mathrm{~mm}$ lateral, $2.8 \mathrm{~mm}$ depth). After 2 weeks, animals were reanesthetized (chloral hydrate) and perfusion fixed (4\% paraformaldehyde, $0.05 \%$ glutaraldehyde, and $15 \% \mathrm{v} / \mathrm{v}$ saturated picric acid in $0.1 \mathrm{M}$ PB). Brains were cut transversely into $70-\mu \mathrm{m}$-thick sections.

Electrophysiological recordings. The illustrated cell was obtained from experiments using male Sprague Dawley rats (250-300 g) anesthetized with urethane $(1.25 \mathrm{~g} / \mathrm{kg}$ body weight), supplemented by ketamine and xylazine ( 20 and $2 \mathrm{mg} / \mathrm{kg}$, respectively) as needed. Body temperature was maintained with a heating pad. Neuronal activity was recorded extracellularly with a glass electrode (15-25 M $\Omega$ ) filled with $1.5 \%$ Neurobiotin in $0.5 \mathrm{M} \mathrm{NaCl}$. The local field potential (LFP) was recorded with a nearby second electrode in stratum radiatum. Single-unit activity (sampling, 20 $\mathrm{kHz}$ ) and LFPs (sampling, $1 \mathrm{kHz}$ ) were filtered online (NPI Electronic) between $0.8-5 \mathrm{kHz}$ and $0.3-300 \mathrm{~Hz}$, respectively. Neurons were labeled with Neurobiotin using the juxtacellular labeling method (Pinault, 1996). Four hours after labeling, the animals were perfusion fixed (as above). In addition, silicon probes (50 or $100 \mu \mathrm{m}$ distance between recording sites; NeuroNexus Technologies) were used to detect LFPs (sampling, $0.1 \mathrm{~Hz}$ to $6 \mathrm{kHz}$ ) radially from the white matter to the fissure $(n=$ 3).

Histological analysis. Antibodies against the following molecules were used: vasoactive intestinal polypeptide (VIP), parvalbumin (PV), acetycholine muscarinic receptor-2, neurokinin receptor-1 (NK1), GABA receptor $\alpha 1$-subunit (GABA- $\alpha 1$ ), somatostatin (SM), cholecystokinin (CCK), cannabinoid receptor-1 (CB1), glutamic acid decarboxylase (GAD65, GAD67), EGFP, metabotropic glutamate receptor- $1 \alpha$ (mGluR1 $\alpha$ ), calbindin $(\mathrm{CB})$, calretinin $(\mathrm{CR})$, neuropeptide $\mathrm{Y}$, chicken ovalbumin up-stream promoter transcription factor-II (COUP-TFII), choline acetyltransferase (ChAT), glycine transporter-2 (GlyT2), vesicular acetylcholine transporter (vAChT), vesicular inhibitory amino acid transporter (VIAAT), and proenkephalin (ENK). The latter antiserum raised to residues 251-269 of rat preproenkephalin recognizes both Metenkephalin and proenkephalin (Lee et al., 1997) (supplemental Table 1, available at www.jneurosci.org as supplemental material). Secondary antibodies were conjugated to Alexa Fluor-488 (Invitrogen), AMCA (7amino-4-methylcoumarin-3-acetic acid), Cy3, or Cy5 (Jackson Laboratories). Immunopositive cells were counted by epifluorescence microscopy using $70 \mu \mathrm{m}$-sections from three male Sprague Dawley rats $(250-350 \mathrm{~g})$, and reacted for up to four antibodies using different fluorophores and photographing each ENK-expressing cell ( $40 \times$ objective) on both surfaces of the section in random, nonoverlapping fields.

For electron microscopy, sections were processed by a horseradish peroxidase enzyme reaction, in some cases double reacted using $\mathrm{Ni}$ intensified DAB reaction for Neurobiotin and only DAB for parvalbumin immunoreaction, followed by osmium treatment, dehydration, and mounting in epoxy resin (Ferraguti et al., 2005). All axons in the plane of electron microscopic sections from three blocks were monitored in serial sections ensuring random sampling of synapses. Pyramidal cell dendrites were identified by electron-opaque intracellular protein aggregates, emerging spines, and absence of type-I synapses onto their shafts. Interneurons were defined by receiving type-I synapses on dendritic shafts and somata.

Data analysis. Detection of theta, nontheta/nonsharp waves, gamma, and ripple episodes, and the calculation of discharge frequencies of single cells during different brain states was achieved as described previously (Tukker et al., 2007) using custom-built scripts in Spike2 (version 6.02; Cambridge Electronic Design). Bursts of action potentials were defined as clusters of at least three action potentials discharged at frequencies $>100 \mathrm{~Hz}$. Theta and gamma phase were analyzed using circular statistics. Significant differences were accepted at $p<0.05$.

\section{Results}

To test for nonpyramidal projection cells, we used a sensitive EGFP-expressing recombinant viral vector (Tomioka and Rockland, 2006) for retrograde labeling from the dorsal subicular area $(n=4)$. ENK-immunopositive cells $(11.3 \%)$ were among the hippocampo-subicular nonpyramidal projection population $(n=62)$, as detected by the colocalization of EGFP and ENK (Fig. $1 A)$. All tested ENK-expressing hippocampo-subicular cells $(n=$ 7) were colabeled for the nuclear receptor COUP-TFII, but none for the $\mathrm{Ca}^{2+}$-binding protein CR. The ENK-expressing hippocampo-subicular cells were located in middle $(n=3)$ and deep $(n=4)$ stratum radiatum, close to stratum lacunosum moleculare (Fig. $1 \mathrm{~B})$.

To ascertain whether ENK-expressing cells in stratum radiatum were GABAergic, they were tested by in situ hybridization for the expression of GAD mRNA by autoradiography (supplemental Fig. 1, available at www.jneurosci.org as supplemental material). The majority $(93.5 \%)$ of ENK-expressing cells $(n=46)$ in stratum radiatum coexpressed mRNA for GAD, in agreement with GABA-immunoreactivity in ENK-positive synaptic terminals (Blasco-Ibáñez et al., 1998). This establishes the GABAergic nature of the ENK-expressing projection to the subiculum.

Some interneuron-targeting cells express ENK (BlascoIbáñez et al., 1998). Therefore, we examined its coexpression with other molecules reported in such interneurons (Acsády et al., 1996; Gulyás et al., 1996) together with COUP-TFII immunoreactivity. Calretinin immunoreactivity was detected in $48.6 \%$ and VIP in $35.4 \%$ of the ENK-expressing population $(n=144)$ (supplemental Fig. 2, available at www.jneurosci. org as supplemental material). However, ENK-expressing cells colabeled for both CR and VIP were rare (16\%). The nuclear receptor COUP-TFII was frequently coexpressed (88\%) with ENK $(n=144)$, and mGluR $1 \alpha(33 \%)$ was also found in a subset of ENK-expressing cells $(n=80)$, always associated with COUP-TFII (data not shown).

To determine axodendritic distributions and activity patterns of ENK-expressing hippocampo-subicular cells, juxtacellular 

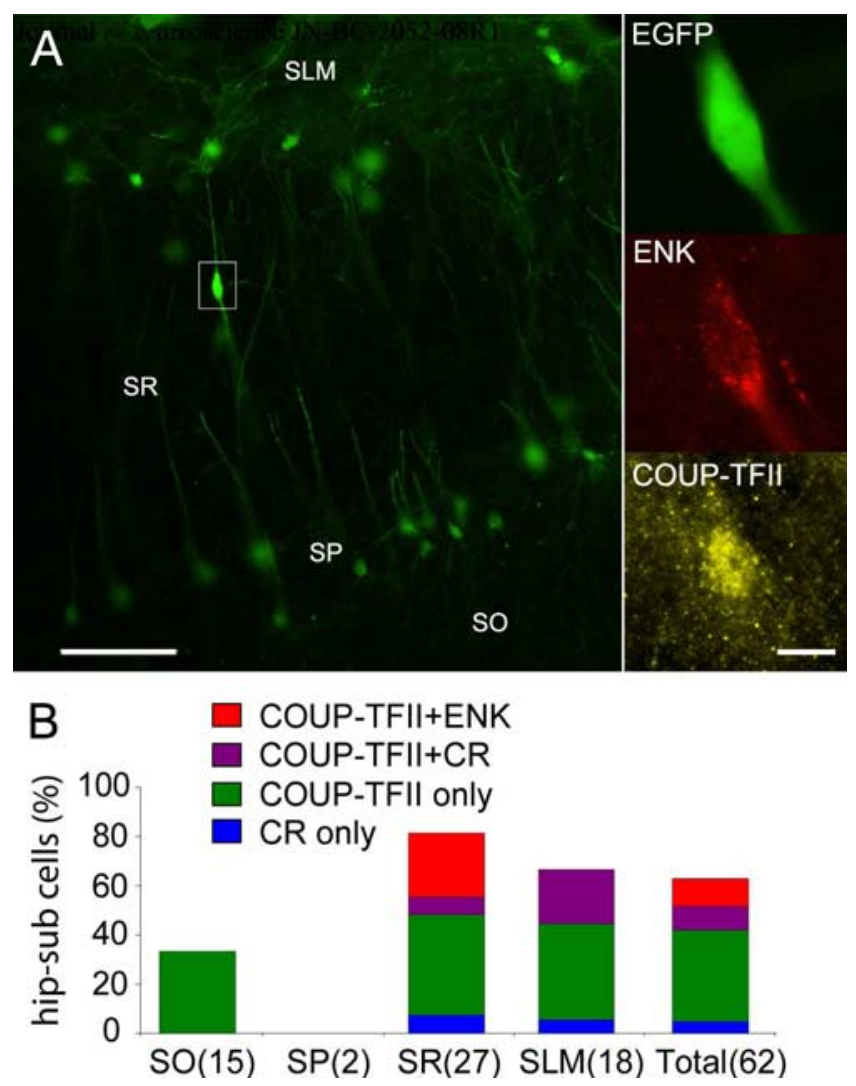

Figure 1. ENK-expressing cells project to the subiculum. $\boldsymbol{A}$, Left, Fluorescent micrographs of hippocampo-subicular projection neurons in the CA1 area detected by EGFP immunofluorescence and retrogradely labeled after a recombinant adenovirus vector injection in the subiculum. Right, Expression of ENK and COUP-TFIl in one hippocampo-subicular cell from the left. $\boldsymbol{B}$, Colocalization of molecular markers by layer on ENK-expressing cells outside stratum pyramidale (number of counted cells). SLM, Stratum lacunosum moleculare; SR, stratum radiatum; SP, stratum pyramidale; SO, stratum oriens. Scale bars: $A$, left, $100 \mu \mathrm{m}$; right, $10 \mu \mathrm{m}$.

labeling was performed in anesthetized rats. Given the scarcity of ENK-expressing hippocampo-subicular cells, only one cell could be positively identified (Fig. 2). Its radially elongated soma was located in the middle of stratum radiatum, exhibiting thin smooth dendrites radially projecting to alveus and to the border with stratum lacunosum moleculare (Fig. 2C). The axon branched profusely around the soma, studded with varicosities. Descending branches gave off a very long horizontal plexus, restricted to the stratum oriens/alveus and the white matter, in opposite mediolateral and rostrocaudal directions, over long distances (mediolateral length $2.5 \mathrm{~mm}$ ) (Fig. 2C). Alvear axon collaterals running in the white matter reached and innervated the deepest layer of the subiculum as it emerged under stratum oriens of the CA1 area.

The identified cell was tested for 17 molecules and its targets for two additional molecules in 38 immunohistochemical tests (several antibodies tested against the same molecule) using multichannel immunofluorescence reactions, epifluorescence, and confocal microscopy on several sections. The soma of the cell was immunopositive for ENK and COUP-TFII (Fig. $2 A$ ) and the somatodendritic plasma membrane for mGluR $1 \alpha$. The dendrites were immunonegative for PV, CR, VIP, CCK, NK1, M2, and $\mathrm{GABA}_{\mathrm{A}}-\alpha 1$ receptors. The dendrites received VIP-positive inputs, but were not contacted by CR- or PV-positive inputs. Neither were they in contact with CR-positive dendrites. The Neurobiotin-labeled axon was immunonegative for PV, CR,
CCK, VIP, vAChT, ChAT, GlyT2, CB1, and GAD (tested with two antibodies). The latter is surprising, but judging from the relatively low level of GAD mRNA in the soma of many ENKpositive cells, the terminals may express levels of GAD undetectable with our methods and antibodies. The axon terminals tested for VIAAT were immunopositive (Fig. $2 \mathrm{~B}$ ).

Double-immunofluorescent reactions were performed to characterize potential postsynaptic targets in view of the expression of ENK in interneuron-selective cells (Blasco-Ibáñez et al., 1998). The most frequently targeted and heavily innervated interneurons (Fig. 2D) were PV-expressing cells (5/6 tested target cells). Four PV-positive neurons and three other neurons with high levels of endogenous biotin content (characteristic of parvalbumin-expressing cells) received an average of $11 \pm 9$ boutons on the soma and proximal dendrites (range 2-32). Other interneurons, such as CR- (one of three) and VIP-expressing cells (one of four) were less frequently innervated, whereas CB- (zero of four), CCK- (zero of three), SM- (zero of four), and mGluR1 $\alpha$ immunoreactivity (zero of two) was not found in cells contacted by boutons. Three targeted PV-positive cells were SM negative, thereby excluding that they could be bistratified or orienslacunosum moleculare cells (Klausberger and Somogyi, 2008). Because the large horizontal plexus in the alveus overlaps with the horizontal dendrites of M2- or mGluR $1 \alpha$-expressing interneurons (Hájos et al., 1998), two-channel fluorescence search was made for potential selective alignment between the axon of the identified ENK-expressing cell and immunopositive dendrites, but no evidence of selective innervation was found (data not shown).

To establish the identity of postsynaptic structures of the identified ENK-expressing cell, random samples of its boutons making 57 synapses were evaluated by electron microscopy (Fig. 2E-G; supplemental Table 2, available at www.jneurosci. org as supplemental material). A single bouton could give more than one synaptic junction to each target and usually displayed large synaptic areas. In the CA1 area $(n=50$ synapses), preferred synaptic targets were interneurons (57\%), and cell-type preferences were layer dependent. In the alveus and stratum oriens proximal to it, the majority of targets (93\%) were interneurons ( $n=10$ dendritic shafts, 3 somata), whereas in the rest of strata oriens and radiatum $(n=16)$, the main targets were pyramidal cell dendritic shafts $(81 \%)$. In stratum pyramidale ( $n=19$ synapses), most targets were interneurons $(65 \%)$ and included an innervated interneuron cell body ( $n=8$ synapses) (Fig. $2 E)$, three interneuron dendrites, including two on a parvalbumin-positive dendrite (supplemental Fig. 3, available at www.jneurosci.org as supplemental material), five pyramidal cell dendrites, two unidentified dendrites, and one pyramidal cell soma. In the subiculum, where the axonal plexus was restricted to the alveus and white matter, all synaptic targets were interneurons $(n=$ 7 dendritic shafts). Interneuron innervation was both selective and extensive; the interneuron in Figure $2 D$ was innervated by 32 axonal varicosities on the soma and proximal dendrites.

Finally, spike timing was recorded during network oscillations (Fig. $3 A, B$ ). The identified ENK-expressing cell was active throughout the recording, with discharge frequencies of 4.1, 0.5 , and $5.5 \mathrm{~Hz}$ for theta, ripple, and nontheta/nonripple episodes, respectively. During theta oscillations $(4.5 \pm 0.6$ $\mathrm{Hz})$, the cell was distinctly modulated ( $r=0.35$; Rayleigh test, $p<0.0001$ ) and fired at $242 \pm 75^{\circ}$ (mean phase \pm angular deviation) relative to the troughs of the theta waves detected from a nearby second electrode; field potentials recorded by 


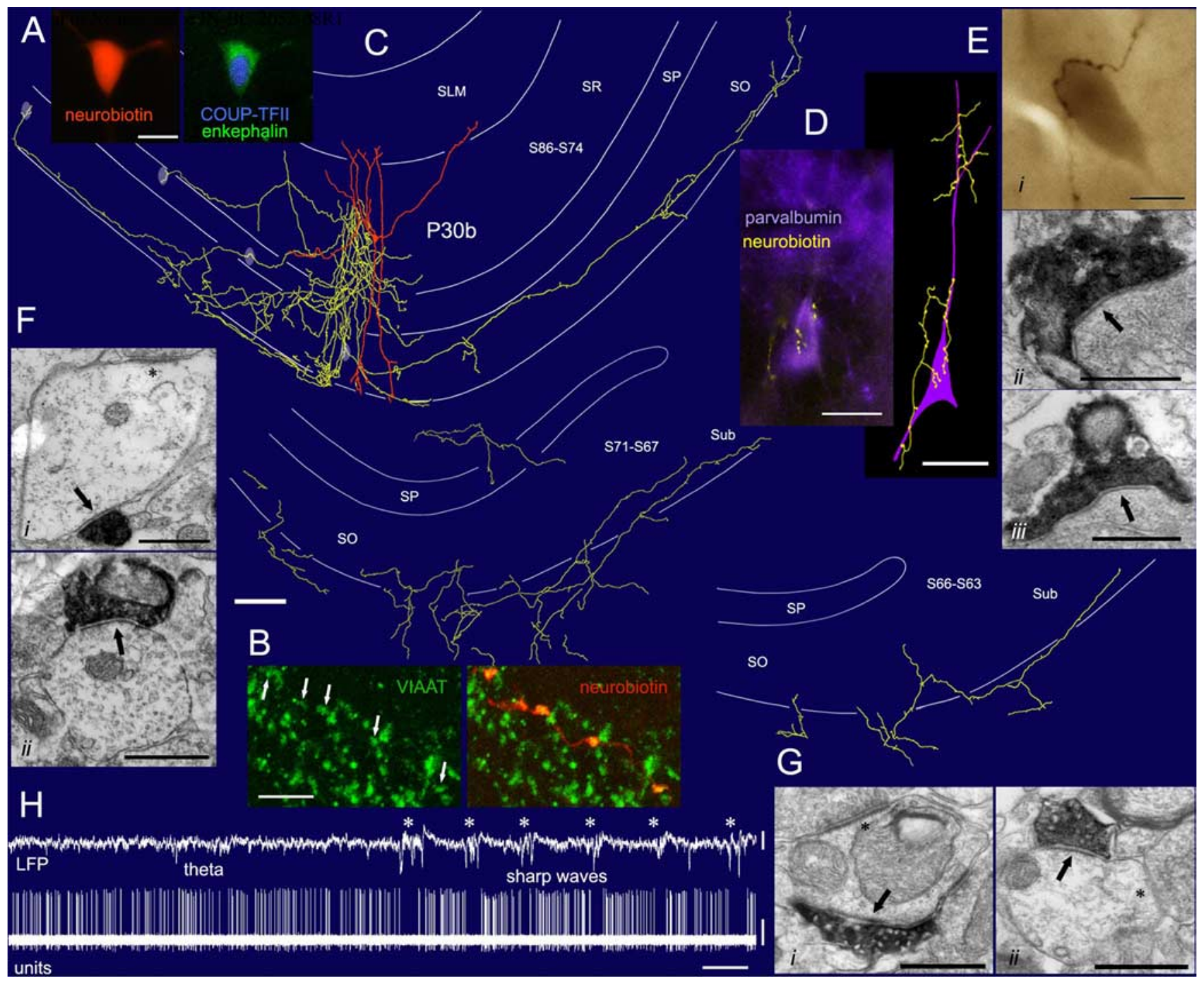

Figure 2. Subicular projection and synaptic output of an identified ENK-expressing interneuron (P30b) recorded in vivo. A, Somatic expression of COUP-TFII (nucleus) and ENK-immunoreactivity. $B$, VIAAT-immunoreactivity in the axon terminals. $C$, Reconstruction of the cell. The dendritic arbor (orange) is complete; the axon (yellow) is presented partially in three panels from rostral (section 86) to caudal (section 63) levels. The axon formed a columnar arbor near the soma and an elongated plexus ( $2.5 \mathrm{~mm}$ ) in the alveus, continuing into and innervating the subiculum. Four light ellipses depict the location of some synaptically targeted interneurons. $\boldsymbol{D}$, A parvalbumin-positive interneuron (purple) in stratum pyramidale is selectively innervated on the soma and proximal dendrites by 32 boutons of the interneuron (yellow), as shown in a fluorescent micrograph (left) and a tracing after HRP conversion (right). Ei, A strongly endogenous biotin-containing interneuron in stratum pyramidale is innervated by seven boutons of the identified ENK-expressing cell. Eii, Eiii, Electron micrographs show two boutons making type-Il synapses (arrows) on the same soma. Fi, Fii, Electron micrographs show type-Il synapses (arrows) onto dendritic shafts of an interneuron (Fi) and a pyramidal cell (Fii) and in stratum radiatum. The asterisk indicates a type-I synapse. Gi, Gii, Electron micrographs show type-ll synapses (arrows) onto dendritic shafts of subicular interneurons identified by type-I synapses on the dendritic shafts (asterisks) in these or the following sections. $\boldsymbol{H}$, Example trace of the LFP $(0.3-300 \mathrm{~Hz}$ ) and spike train (units, $0.8-5 \mathrm{kHz}$ ) of the ENK-expressing cell during theta oscillations and sharp waves (asterisks). SO, Stratum oriens; SP, stratum pyramidale; SR, stratum radiatum; SLM, stratum lacunosum moleculare; Sub, subiculum. Scale bars: $A, 10 \mu \mathrm{m} ; \boldsymbol{B}, 5 \mu \mathrm{m} ; \boldsymbol{C}, 100 \mu \mathrm{m} ; \mathbf{D}-E \mathbf{E}, 20 \mu \mathrm{m} ;$ Eii-G, $0.5 \mu \mathrm{m}$. Calibration: H, LFP, $1 \mathrm{mV}, 2 \mathrm{~s}$; units, $0.5 \mathrm{mV}, 2 \mathrm{~s}$.

the two electrodes were identical. From silicon probe recordings in additional experiments $(n=3)$, it is expected that the theta phase at this site is advanced by $34 \pm 11^{\circ}$ relative to the cycles recorded from stratum pyramidale, suggesting that the highest firing rate of the cell was at around $208^{\circ}$ of the theta waves in stratum pyramidale. During gamma oscillations $(42 \pm 9 \mathrm{~Hz})$, the cell was weakly modulated $(r=0.05$; Rayleigh test, $p<0.01)$ and discharged at $55 \pm 79^{\circ}$ relative to the locally detected gamma oscillations, which were in phase at both electrodes. During ripple episodes $(107 \pm 12 \mathrm{~Hz})$, the cell strongly decreased its firing rate and remained silent in $99 \%$ of ripples $(n=80)$. Interestingly, briefly after many ripple episodes, the cell exhibited rebound activity, significantly increasing ( $p=$ $0.001)$ its discharge rate $(6.6 \pm 2.5$ spikes/bin $)$ compared with that before ripple episodes $(4.4 \pm 1.6$ spikes/bin) (Fig. $3 B)$. Such increase in firing rate was mostly caused by burst discharges (Fig. 3C), which took place after ripple episodes (delay, $223 \pm 125 \mathrm{~ms}$; frequency, $204 \pm 52 \mathrm{~Hz}, n=48$; considering only bursts occurring within $0.5 \mathrm{~s}$ after ripple episodes) (Fig. 3C; supplemental Fig. 4, available at www.jneurosci. org as supplemental material).

\section{Discussion}

We have identified an ENK-expressing GABAergic neuronal population in the hippocampal CA1 field that projects to the subicular area. Despite their seemingly small number, hippocampo-subicular ENK-expressing cells might contribute to regulating hippocampal network activity because of distinct fea- 

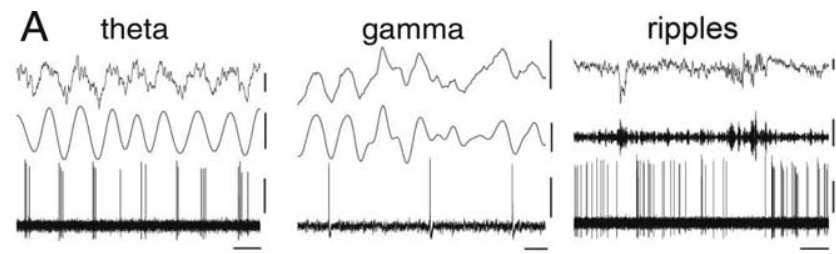

B
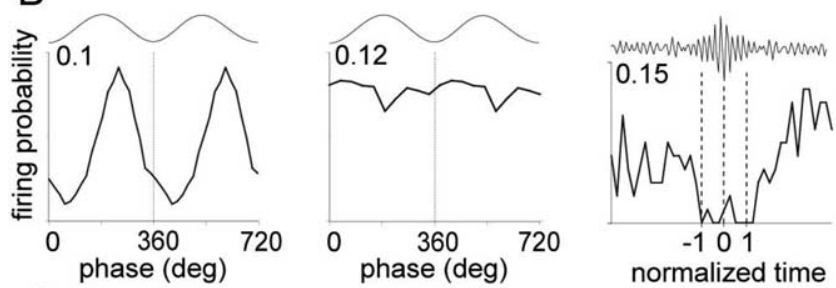

C
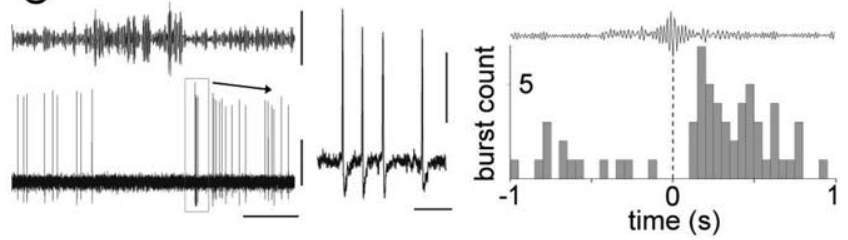

Figure 3. Spike timing of an identified ENK-expressing hippocampo-subicular cell during spontaneous network oscillations. $\boldsymbol{A}$, Firing patterns (top, LFP; middle, LFP filtered; bottom, units) during theta (LFP filtered $3-6 \mathrm{~Hz}$ ), gamma (LFP filtered $30-80 \mathrm{~Hz}$ ), and sharp-wave-associated ripple (LFP filtered $90-140 \mathrm{~Hz}$ ) oscillations recorded by a reference electrode located in stratum radiatum. $\boldsymbol{B}$, Phase histograms of spikes in relation to locally detected oscillation troughs from the reference electrode $\left(0,360\right.$, and $720^{\circ}$; bin size, $18^{\circ}$ for theta and $36^{\circ}$ for gamma). The onset, highest amplitude, and end of normalized ripple episodes are marked as $-1,0$, and 1 , respectively (dotted lines). $\boldsymbol{C}$, Left, Example of a burst discharge after a series of ripple episodes. Middle, The burst discharge at expanded time scale. Right, Perievent histogram showing increased burst discharge after ripple episodes ( 0 s indicates highest ripple amplitude; $n=80$ ). Bin size, $50 \mathrm{~ms}$. Calibrations: $\boldsymbol{A}$, theta, top, $0.5 \mathrm{mV}$; middle, $0.5 \mathrm{mV}$; bottom, $0.5 \mathrm{mV}$; horizontal, $200 \mathrm{~ms}$; gamma, top, $0.5 \mathrm{mV}$; middle, $0.2 \mathrm{mV}$; bottom, $0.5 \mathrm{mV}$; horizontal, $20 \mathrm{~ms}$; ripples, top, 0.5 $\mathrm{mV}$; middle, $0.1 \mathrm{mV}$; bottom, $0.5 \mathrm{mV}$; horizontal, $500 \mathrm{~ms}$; $\boldsymbol{C}$, left, top, $0.1 \mathrm{mV}, 200 \mathrm{~ms}$; bottom, $0.5 \mathrm{mV}, 200 \mathrm{~ms}$; inset, $0.5 \mathrm{mV}, 10 \mathrm{~ms}$.

tures such as their subicular projection, ENK release, and interneuron-target selectivity.

Enkephalin expression has been described as restricted to interneuron-selective cells, which also coexpress CR and VIP, and which have axons innervating mainly ENK- or CBexpressing interneurons, but not PV-positive cells (BlascoIbáñez et al., 1998). Differences in antibodies and methods might account, at least partially, for our different experimental results. Blasco-Ibáñez et al. (1998) used an antibody to Met-enkephalin, whereas we used an antibody that in addition recognizes the precursor protein (Lee et al., 1997), and the latter may reveal more cell bodies. Indeed, in our experiments, approximately one-third of ENK-expressing cells were not CR- or VIP-immunopositive, suggesting that ENK-expressing cells may be neurochemically diverse. Calretinin was found in nearly half of ENK-expressing cells, but it has not been found in ENK-positive projection cells suggesting that ENK- and CR-expressing cells might be different from ENK-positive projection cells.

Neurons expressing ENK have not been described among the extrahippocampal projecting GABAergic populations (Blasco-Ibáñez et al., 1998; Jinno and Kosaka, 2002; Miyashita and Rockland, 2007). Their identity as projection neurons is now clearly established by retrograde labeling and the corroborative features of the ENK-expressing cell recorded and la- beled in vivo. The small number of ENK-positive neurons projecting to the subiculum that we detected is probably an underestimation, because our subicular injections were relatively small and would have labeled only a fraction of axonal terminals in the subiculum.

Opioid release in the brain is $\mathrm{Ca}^{2+}$-dependent (Chavkin et al., 1983) and likely requires high-frequency discharge of the presynaptic terminal (Wagner et al., 1991; Terman et al., 1994). Therefore, ENK signaling, involving both $\mu$ and $\delta$ opioid receptors in the hippocampus, is frequency dependent, and the burst discharges shown in this study suggest that ENK might be rhythmically released during theta oscillations as well as preferentially at the end of ripple episodes. Remarkably, the identified ENK-expressing cell was virtually silent during ripple episodes although its dendrites spanned strata oriens and radiatum, where the incoming volley of CA3 afferents releases glutamate during sharp waves, suggesting the activation of a powerful feedforward inhibitory input to ENK neurons. However, after termination of ripple episodes, a clear rebound in activity was observed that was different from firing exhibited before ripple episodes. After ripples, firing consisted mainly of bursts of action potentials at up to $200 \mathrm{~Hz}$, generating an optimal context for ENK release. Given the wide extension of the axonal arbor, target selectivity and short time window after ripple episodes when the identified ENK-expressing cell concentrated its activity, it is expected that the concerted release of ENK from other similar cells will have a profound effect in the hippocampal network (Zieglgänsberger et al., 1979; Nicoll et al., 1980).

The identified ENK-expressing cell is the first local interneuron identified with a target preference for PV-positive interneurons. The absence of SM-expression in PV-positive targets suggests that they are axoaxonic and/or basket cells, which express high levels of $\mu$ opioid receptors in their somatodendritic membranes (Stumm et al., 2004) as well as on their terminals. From their large size and dense somatic synaptic cover, at least some of them can be inferred to be basket cells.

The specialization of ENK-expressing cells could support a control mechanism that modulates the activity of basket cells during hippocampal network activity by fast GABAergic synaptic transmission, as well as by the slowly acting ENKs. Such a double inhibitory system might be suitable for controlling processes in different time scales, such as spike timing (fast) and synaptic plasticity (slow). Interestingly, basket cells are very active throughout ripple episodes, when the ENK-expressing cell was silent. In contrast, axoaxonic cells increase their discharge frequency around the onset (Klausberger and Somogyi, 2008) but, like the ENK-expressing cell, are silent at the peak of the ripple. Because the activity of basket and bistratified cells seems to control the precise timing of ripple-coupled pyramidal cell firing, it is possible that the sharp decrease in activity of some ENKexpressing cells is a contributing factor not only to the development of ripples, but also to their coordination between the CA1 and subicular areas. Future recordings of further identified ENKpositive projection cells should test these predictions, which at present derive partially from results obtained on a single identified cell.

\section{References}

Acsády L, Görcs TJ, Freund TF (1996) Different populations of vasoactive intestinal polypeptide-immunoreactive interneurons are specialized to control pyramidal cells or interneurons in the hippocampus. Neuroscience 73:317-334. 
Blasco-Ibáñez JM, Martínez-Guijarro FJ, Freund TF (1998) Enkephalincontaining interneurons are specialized to innervate other interneurons in the hippocampal CA1 region of the rat and guinea-pig. Eur J Neurosci 10:1784-1795.

Chavkin C, Bakhit C, Weber E, Bloom FE (1983) Relative contents and concomitant release of prodynorphin/neoendorphin-derived peptides in rat hippocampus. Proc Natl Acad Sci U S A 80:7669-7673.

Ferraguti F, Klausberger T, Cobden P, Baude A, Roberts JD, Szucs P, Kinoshita A, Shigemoto R, Somogyi P, Dalezios Y (2005) Metabotropic glutamate receptor 8-expressing nerve terminals target subsets of GABAergic neurons in the hippocampus. J Neurosci 25:10520-10536.

Gall C, Brecha N, Karten HJ, Chang KJ (1981) Localization of enkephalinlike immunoreactivity to identified axonal and neuronal populations of the rat hippocampus. J Comp Neurol 198:335-350.

Gulyás AI, Hájos N, Freund TF (1996) Interneurons containing calretinin are specialized to control other interneurons in the rat hippocampus. J Neurosci 16:3397-3411.

Hájos N, Papp EC, Acsády L, Levey AI, Freund TF (1998) Distinct interneuron types express $\mathrm{m} 2$ muscarinic receptor immunoreactivity on their dendrites or axon terminals in the hippocampus. Neuroscience 82:355-376.

Hughes J, Smith TW, Kosterlitz HW, Fothergill LA, Morgan BA, Morris HR (1975) Identification of two related pentapeptides from the brain with potent opiate agonist activity. Nature 258:577-580.

Jinno S, Kosaka T (2002) Immunocytochemical characterization of hippocamposeptal projecting GABAergic nonprincipal neurons in the mouse brain: a retrograde labeling study. Brain Res 945:219-231.

Jinno S, Klausberger T, Marton LF, Dalezios Y, Roberts JD, Fuentealba P, Bushong EA, Henze D, Buzsáki G, Somogyi P (2007) Neuronal diversity in GABAergic long-range projections from the hippocampus. J Neurosci 27:8790-8804

Klausberger T, Somogyi P (2008) Neuronal diversity and temporal dynamics: the unity of hippocampal circuit operations. Science 321:53-57.

Lee T, Kaneko T, Taki K, Mizuno N (1997) Preprodynorphin-, preproenkephalin-, and preprotachykinin-expressing neurons in the rat neostriatum: an analysis by immunocytochemistry and retrograde tracing. J Comp Neurol 386:229-244.
Madison DV, Nicoll RA (1988) Enkephalin hyperpolarizes interneurones in the rat hippocampus. J Physiol 398:123-130.

Miyashita T, Rockland KS (2007) GABAergic projections from the hippocampus to the retrosplenial cortex in the rat. Eur J Neurosci 26:1193-1204.

Morales M, Bloom FE (1997) The 5-HT3 receptor is present in different subpopulations of GABAergic neurons in the rat telencephalon. J Neurosci 17:3157-3167.

Nicoll RA, Alger BE, Jahr CE (1980) Peptides as putative excitatory neurotransmitters: carnosine, enkephalin, substance P and TRH. Proc R Soc Lond B Biol Sci 210:133-149.

Pang K, Rose GM (1989) Differential effects of methionine5-enkephalin on hippocampal pyramidal cells and interneurons. Neuropharmacology 28:1175-1181.

Pinault D (1996) A novel single-cell staining procedure performed in vivo under electrophysiological control: morpho-functional features of juxtacellularly labeled thalamic cells and other central neurons with biocytin or neurobiotin. J Neurosci Methods 65:113-136.

Stumm RK, Zhou C, Schulz S, Höllt V (2004) Neuronal types expressing $\mathrm{mu}$ - and delta-opioid receptor mRNA in the rat hippocampal formation. J Comp Neurol 469:107-118.

Terman GW, Wagner JJ, Chavkin C (1994) Kappa opioids inhibit induction of long-term potentiation in the dentate gyrus of the guinea pig hippocampus. J Neurosci 14:4740-4747.

Tomioka R, Rockland KS (2006) Improved Golgi-like visualization in retrogradely projecting neurons after EGFP-adenovirus infection in adult rat and monkey. J Histochem Cytochem 54:539-548.

Tukker JJ, Fuentealba P, Hartwich K, Somogyi P, Klausberger T (2007) Cell type-specific tuning of hippocampal interneuron firing during gamma oscillations in vivo. J Neurosci 27:8184-8189.

Wagner JJ, Evans CJ, Chavkin C (1991) Focal stimulation of the mossy fibers releases endogenous dynorphins that bind kappa 1-opioid receptors in guinea pig hippocampus. J Neurochem 57:333-343.

Waldhoer M, Bartlett SE, Whistler JL (2004) Opioid receptors. Annu Rev Biochem 73:953-990.

Zieglgänsberger W, French ED, Siggins GR, Bloom FE (1979) Opioid peptides may excite hippocampal pyramidal neurons by inhibiting adjacent inhibitory interneurons. Science 205:415-417. 